\title{
The Art Experience
}

\section{Kate McCallum ${ }^{1} \cdot$ Scott Mitchell ${ }^{1} \cdot$ Thom Scott-Phillips $^{2,3}$}

Published online: 18 July 2019

(C) The Author(s) 2019

\begin{abstract}
Art theory has consistently emphasised the importance of situational, cultural, institutional and historical factors in viewers' experience of fine art. However, the link between this heavily context-dependent interpretation and the workings of the mind is often left unexamined. Drawing on relevance theory - a prominent, cogent and productive body of work in cognitive pragmatics - we here argue that fine art achieves its effects by prompting the use of cognitive processes that are more commonly employed in the interpretation of words and other stimuli presented in a communicative context. We describe in particular how institutional factors effectively co-opt these processes for new ends, allowing viewers to achieve cognitive effects that they otherwise would not, and so provide cognitivist backing for an Institutional Theory of Art, such as that put forward by Arthur Danto (1964). More generally, we situate and describe the Western fine art tradition as a phenomenon that is a consequence of both the cognitive processes involved in communication, and of cultural norms, practices and institutions.
\end{abstract}

\section{Introduction}

When confronted by a piece of art, viewers often entertain rich, surprising and complex thoughts, and this interpretive process occurs across otherwise very different prompting phenomena. Moreover, viewers often interpret artworks in ways that go well beyond how they would interpret the same object encountered in a different cultural context. Take for a particularly dramatic and unusual example the case of readymades, a term for a form of making made popular by Marcel Duchamp in the early twentieth century in which ordinary objects were appropriated and displayed as art. The objects were often perfectly everyday ones that nobody would look twice at in a different context.

Thom Scott-Phillips

thom.scottphillips@gmail.com

1 University of Brighton, Brighton, England

2 Department of Cognitive Science, Central European University, Budapest, Hungary

3 Department of Anthropology, Durham University, Durham, UK 
How can the involved and intricate interpretative process accorded to works of art be inspired by such objects? Our goal here is to help answer this question by using insights from cognitive pragmatics and the philosophy of language to augment institutional theories of art, and to show how this approach casts light on the art experience more broadly. To be clear, this is not intended as an account of creativity, nor a manifesto for how art should be interpreted, or how the art world ought to be. We are concerned instead with explaining how the viewer's experience of fine art already does function from a cognitive point of view.

To elaborate with a specific example, consider Duchamp's Bottle Rack (1914). The object itself is perfectly ordinary and functional: a spiky metal rack used for the drying of bottles. The artist did not put any physical labour into its construction nor design. A person might encounter this same object in a dusty cupboard and see only a functional tool. Perhaps if a person visited an antique-collecting friend's house, and this friend picked up this object and showed it to her, his intentional displaying of the object might lead her to assume that she was meant to admire his latest find. But walking into the Moderna Museet in Sweden, with its clean white walls and hushed attendants, and finding this object placed carefully on a clean white plinth with a famous name on a tag next to it, suddenly a very different kind of explanation is sought for why this object is there-an explanation that is rather unique in its character. Take, for example, the interpretation offered by Andrew Graham-Dixon, in episode three of his BBC4 series 'The Art of France':

"Duchamp was fascinated by the idea that man is prisoner of his sexual impulses. Could this be Duchamp's way of suggesting that everyone alive - every man, at least - is caught in a state of priapic longing, forever suspended, waiting for the moment of sexual conjunction with the female bottle?" (Graham-Dixon 2017, emphasis in original)

There is an obvious question here: what is it that prompts this kind of creative interpretation? It becomes evident in the case of a work like Bottle Rack that meanings are not inherent in the object, but are teased out by the viewer when considering why the great artist has placed this thing in this place in this way.

We shall argue that the cognitive processes involved in interpretation are, largely, also those that are more typically employed in ordinary, day-to-day communication. When an object is displayed as an art object, a kind of intentionality is attributed to the artist that goes beyond the more straightforward intentions displayed by the antiquecollecting friend. This evidence of intention provides motivation to seek out effortful interpretations, which may in consequence be rich and varied. In addition, the art-world framing legitimates a viewer's entertaining multiple, speculative interpretations without resolving them. In such ways the highly artificial gallery setting prompts a reverential way of approaching art - one that could be called an 'art experience'. Our general approach is nearby to that advocated by Deirdre Wilson for literature (2018) and Alessandro Pignocchi for art (2014a; 2019) in considering these forms of expression as making use of loose or weak communication. Our position develops this perspective further, in particular by suggesting that the revered position of art in culture is surprisingly and crucially implicated in individual experience, facilitating the complex, profound interpretive experiences that set art apart. 
In $\S 2$ we describe human communication as a diverse family of different means by which we express and recognise intentions, and we highlight the compatibility of this approach with institutional perspectives on art. In $\S 3$ we describe in cognitive terms how evidence of communicative intent can encourage an audience to give credence to artwork and hence seek interpretations beyond those they otherwise would. In $\S 4$ we describe how institutions facilitate this process, thereby address the question posed by some other theorists (e.g. Buekens and Smit 2018) of how institutions might participate in art appreciation. In $\S 5$ we emphasise the skill that contemporary artists must have to produce artworks able to reward the search for worthwhile cognitive effects and we illustrate with examples some of the common features of how audiences experience, interpret and otherwise engage with art. In these ways we build new bridges between the cognitive sciences on the one hand, and the humanities on the other.

\section{Interpretation in the Round}

We situate our work within relevance theory, a cognitive account of human communication according to which the interpretation of stimuli perceived as ostensive (see below) is guided by heuristic estimates about the signallers' intentions and the anticipated quantity and quality of the cognitive effects that might be achieved. Cognitive effects can include strengthening or contradicting an existing belief, such that new information follows; and factors that can affect cognitive effort include, for instance, perceptual salience, ease of retrieval from memory, and linguistic or logical complexity. Relevance is the trade-off between these two factors, effects and effort (Wilson and Sperber 1986; Sperber and Wilson 1995; Wilson and Sperber 2004). This approach has been developed, defended and tested at length over the past 30 or so years, and has been used to help explain a great variety of linguistic, communicative and cognitive phenomena (Sperber and Wilson 1995; Carston 2002; Wilson and Sperber 2012; Clark 2013; Yus 2019).

Agreeing with this body of work, we do not view non-linguistic means of communication - raised eyebrows, grunts, pointing and so on - as somehow derivative or impoverished relative to language (McNeill 2005; Kendon 2004; Scott-Phillips 2015a; Wharton 2009; Wharton 2016; Brabanter 2010; Tomasello 2010). Rather, we turn that picture on its head, seeing human communication as a family of different means of expression, all of which are inherently contextual and underdetermined, albeit to different degrees in each case. Linguistic communication is, of course, a crucially important member of that family, but it is best seen as a special case, one that makes use of structured collections of culturally evolved tools (words, grammars) that typically function to make communication more exact and less underdetermined than it otherwise would be (Sperber and Wilson 1995; Sperber and Wilson 2015; Wharton 2009; Scott-Phillips 2017; Carston 2002).

This view of communication aligns closely with the scepticism among many art theorists towards any attempt to identify art with communication in any simple sense; as Theodor Adorno observes, "the contemporary situation of art is hostile to what the jargon of authenticity calls the "message"" (1997, p. 32). Adorno himself wanted to move away from such an understanding and toward a complex and unresolved picture of interpretation, stating that art ought to "set thought processes in motion, not to 
communicate maxims" (ibid.). It is just these kinds of active mental processes that cognitive pragmatics - and relevance theory in particular - recognises and attempts to account for. The transmission of a definite message, or simple retrieval of a speaker's meaning, is for such theories not necessarily the (or even an) outcome of communicative acts. Instead, communication is an activity of overtly raising, in one way or another, the psychological salience (manifestness) of various beliefs, ideas, and other mental states in an audience. This approach allows for a subtle spectrum of conscious and unconscious effects in communication (see in particular Sperber and Wilson 2015).

Thus, we certainly do not claim that art can be 'decoded' in any traditional sense of the word (we do not even believe that ordinary linguistic communication is a matter of decoding alone). Nor do we claim that viewing an artwork is a mirror process to engaging in a conversation. What we do claim is that some cognitive processes are shared across various forms of interpretation, and consequently that it will be fruitful and insightful to compare and contrast interpretation in ordinary conversation with interpretation of art. This approach has recently been used to study literature, with the goal "not to produce better interpretations than actual hearers or readers do, but to explain how they arrive at the interpretations they do construct, whether successfully or unsuccessfully" (Wilson 2011: 4). What we are proposing is that a similar project can be pursued with respect to fine art and is likely to be a valuable source of insight and understanding.

Another way to make these points is to say that the openness of interpretation that clearly exists in the case of art is not a departure from everyday interpretation more generally, it is simply (much) more open ended. Ordinary linguistic utterances underdetermine their meaning, often vastly so (Grice 1989 p.31; Recanati 2001; Sperber and Wilson 1995 pp.181-182; Carston 2008). They are, quite typically, multiply ambiguous, and often contain expressions that do not specify their referent at all (e.g. it, she, this, that, to highlight just the most obvious and ubiquitous cases). Indeed utterances are always - can only be - interpreted in context. As such the distinction between interpretation in everyday conversation and the interpretation of art is best understood as a distinction not between encoded messages and something qualitatively distinct, but rather a graded distinction between two subunits in the larger family of human communication.

The key theoretical notion that unifies these different means of human communication is ostension (Sperber \& Wilson, 1986/ 1995; Scott-Phillips 2015a). Ostension is, in essence, the overt expression of intentionality. By being overt, ostensive acts give "two layers of information" (Sperber and Wilson 1995: 50); they point out some piece of information, and they point out that this pointing out was done deliberately, for the audience's benefit. Consider, say, a park bench on which two people, Mary and Peter, sit eating ice cream (Sperber and Wilson 1995: 48-49). Peter leans back and so alters Mary's field of view to include an ice-cream vendor, a stranger and their mutual acquaintance Bill (whom they both dislike). This makes a variety of conclusions available to Mary, most immediately and most obviously that Bill is here, in the park. Note however that Peter might lean back in one of two ways. He might do so in a casual fashion, not revealing to Mary that he has leaned back in order that she sees Bill; or he might do so in a more overt, stylised way, thereby bringing attention not only to Bill, but also to the fact that he (Peter) has leant back so that Mary can see Bill. This makes available to Mary not only the fact that Bill is in the park, but further 
assumptions too, in particular that Peter has noticed Bill, that Peter intends for Mary to see that Bill is in the park, and various other possible conclusions that might follow from this. Ostension is the word used to describe this deliberately overt behaviour.

Crucially, the recognition of ostension does not just bring attention to a stimulus, or to the fact that it has been produced for a particular audience. Ostension also, quite ordinarily, impacts on interpretation itself, extending and altering the kinds of inferences that are derived from the stimulus. In another example, a woman is travelling in a foreign country and exits her hotel in some light, summery clothes (Sperber and Wilson 1995: 51-52). As she walks, she makes eye contact with an old man who looks slowly up towards the sky, which draws her attention to some small clouds. On her first look, these clouds were not of any relevance to her perception of the day as a beautiful one. Now, however, because the old man has drawn her attention to them, the clouds suggest a range of inferences previously unconsidered. The inference that the weather will turn cold and wet is not only made more accessible to her, but conveying this is in fact the most probable reason for his engaging in communication.

Ostension, then, is behaviour that not only makes something deliberately salient, but does so in such a way that it provides an implicit guarantee that interpreting the stimulus is worth the effort required and should produce worthwhile cognitive effects. This insight is known as the Communicative Principle of Relevance and is more exactly stated as: "[e]very ostensive stimulus conveys a presumption of its own optimal relevance" (Wilson and Sperber 2004, p.612). The relevance of these points for understanding the art experience is that if an ordinary object, whether encountered in a gallery or elsewhere, is perceived as having been placed there for the purpose of being interpreted, then the viewer's experience of that object will be formed with some reference to that intentionality. This is, we believe, a much more convincing description of how such an object might be treated as art than any simple picture of communication based upon the encoding and decoding of explicit messages.

Indeed, intentionality has long been an important topic in art theory. Roland Barthes' Death of the Author, for example, famously shifted the focus away from the author and onto the relationship of audience and text (Barthes 1978), a move partially anticipated by Wimsatt and Beardsley (1946) and the New Criticism school. Subsequent analyses of the role of intention in fine art often include some response to Barthes (e.g. Fodor 2012; Farrell 2017). In the philosophy of mind, Jerry Fodor effectively argues that art is ostensive, even though he does not use that word, stating that "artworks are intended to affect audiences in certain ways, and to do so partly in consequence of the audience's recognition of this intention" (Fodor 2012 p.62). The production of art is seen, in consequence, as the making (or choosing) of "interpretable artifacts" (Fodor 2012 pp.66-7).

What we are suggesting is that from a cognitive point of view more ordinary communicative stimuli, such as words, are also "interpretable artifacts"; as such the substantive differences between words and artworks are differences of degree, with one class of objects typically (although not always) more open-ended than the other (see also Pignocchi 2019). Agreeing with Fodor, Barthes, and Pignocchi, we do not claim that artists do or should have clear, conscious intentions about specific content. In fact, it is clear that an artist's intentions are complex and multiple. Nor do we expect viewers to retrieve a particular, unvaried and predictable interpretation. The suggestion is, rather, that the presentation of an object as a work of art is but one instance of ostensive 
behaviour, the proper function of which is to suggest to the audience that increased investment of cognitive effort in interpretation is likely to lead to worthwhile cognitive effects (see also Scott-Phillips 2015b). As we shall elaborate in the following sections, these effects can be speculative, personal, and unverifiable, but they are nevertheless produced by the same set of cognitive processes that are more typically employed in ordinary communication.

The communicative account that we are putting forward here links closely with several key ideas from the world of art theory. In particular, our approach can be read as an account of how an Institutional Theory of Art, such as that put forward by Arthur Danto (1964), might work in cognitive terms. Institutional theories of art argue that an object is a work of art by virtue of its recognition as such by the institutions of art, or its participation in that institutional structure. Danto states that "[to] see something as art requires something the eye cannot descry-an atmosphere of artistic theory, a knowledge of the history of art: an artworld" (Danto 1964), an idea reformulated later by George Dickie: "A work of art in the classificatory sense is 1) an artifact 2) on which some person or persons acting on behalf of a certain social institution (the artworld) has conferred the status of candidate for appreciation" (Dickie 1971: 101, italics added). Jerrold Levinson's "historical account" (1979; 1989) makes similar proposals, albeit with greater emphasis on how artworks reference an artistic canon, rather than their promotion by an institution (see also Bullot and Reber 2013; Fokt 2017). As we shall elaborate in the next two sections, we propose that the institutional framing emphasised in these previous accounts actually helps motivate viewers to have a richer and deeper experience which might not be achieved otherwise, exactly because the artwork has been presented, in Dickie's words, as a "candidate for appreciation".

\section{Credence and Interpretation}

Within a typical gallery setting, artists are not present to engage in the feedback processes that are present in a conversational exchange and so cannot highlight, clarify and specify their intentions (even were they to have conscious access to them). The only stimulus available is the art and the way that it is presented. In addition, the type of intentionality expected in the art world is multiple and unresolvable. This all opens the space of interpretation in interesting ways. The viewer's expectations of relevance are free to be satisfied by interpretations that are contingent, speculative, and often personal, so long as sufficient positive effects are found.

These effects are further reinforced by institutions and institutional modes of discourse, which provide justification for audiences to believe that the artwork on display will bring sufficient cognitive effects, should cognitive effort be invested (§2). In other words, while it is the artist to whom intentions are attributed, and it is the artwork that is taken to represent those intentions, an institutional setting and other forms of endorsement by the art world often have a substantial impact on interpretation. Indeed art-world sanctioning not only justifies the search for cognitive effects but effectively increases the level of ceremony with which an object is treated. At the extremes these institutional effects can be (more or less) 
the only factor necessary for audiences to grant credence to the object. When submitted under the name 'R. Mutt,' Duchamp's urinal (1917; Fig. 1) ${ }^{1}$ was initially rejected outright despite the exhibition's original promise to display every work of art that was submitted. It was only once Duchamp's famous name was associated with the object - that of an artist legitimated by the art establishmentthat it was considered and discussed in the way that it is now (Higgs 2015).

In general, the credence that audiences grant to communicators affects not only whether an audience accepts that an ostensively presented stimulus is relevant, but also how the stimulus is interpreted. Even in ordinary communicative interactions audiences commonly flesh out half-understood stimuli as best they can, or represent them in only partial ways, such as when a viewer of the news hears (and "believes") that "the economy is in stagflation" despite not really knowing what stagflation is (Sperber 1982). This process is not a defect of cognition: on the contrary it plays a crucial role in communication and social interaction (ibid.). However in extremis it can produce "guru effects", in which opaque stimuli prompt audiences to search for additional cognitive effects in order to satisfy high expectations of relevance deriving from high prior confidence in the reputability of the source (Sperber 2010). In contrast, audiences who have little prior confidence in the source will revise down their already moderate expectations of relevance, sometimes to the extent that even trying to make sense of what someone says is not worth the effort (ibid.). We suggest that these credence effects are often critical to the interpretation of artworks, and especially so in institutional contexts. The endorsement provided by a gallery setting increases the credibility of the artist, and hence encourages audiences to invest cognitive effort in interpretation based on the presumption that this will lead to greater cognitive effects.

This institutional authority can, moreover, reinforce attributions of profundity in a self-sustaining way. Individuals sometimes offer public interpretations or endorsements of an artefact, or a text, whose value may otherwise be opaque or unclear. Organisations - not just white-cube galleries, but also religious groups, intellectual schools, and others - can do this too, sometimes simply by displaying or otherwise highlighting the object in question. In doing so they vouch not only for the value of that object, but also for their own authority and reputation (not to mention that of the object's creator). The importance and value of the work is thus made a public indicator of the competence and reliability of the interpreter. Moreover, since the importance of the object is based in part on the creator's reputation as someone competent and reliable, the interpreter's reputation can become intertwined with this also: "The greater this [item's] value and this [communicator's] authority, the more [the interpreter is] justified in joining the process, and the less the tentative and partial character of their interpretations can be seen as a negative reflection on their own intellectual abilities" (Sperber 2010 p.591). This gives communities engaging in this collective endeavour reason to invest in reputation-protecting mental spaces that allow for multiple, speculative, tentative or partial interpretations. This effect spans a range of cultural domains, such as the writings of intellectual gurus, religious texts, and the advancement of science. Artworks as presented in modern white-cube galleries are but one further example.

\footnotetext{
${ }^{1}$ Now thought in fact to have been the work of Baroness Elsa von Freytag-Loringhoven, later appropriated by Duchamp (Higgs 2015)
} 


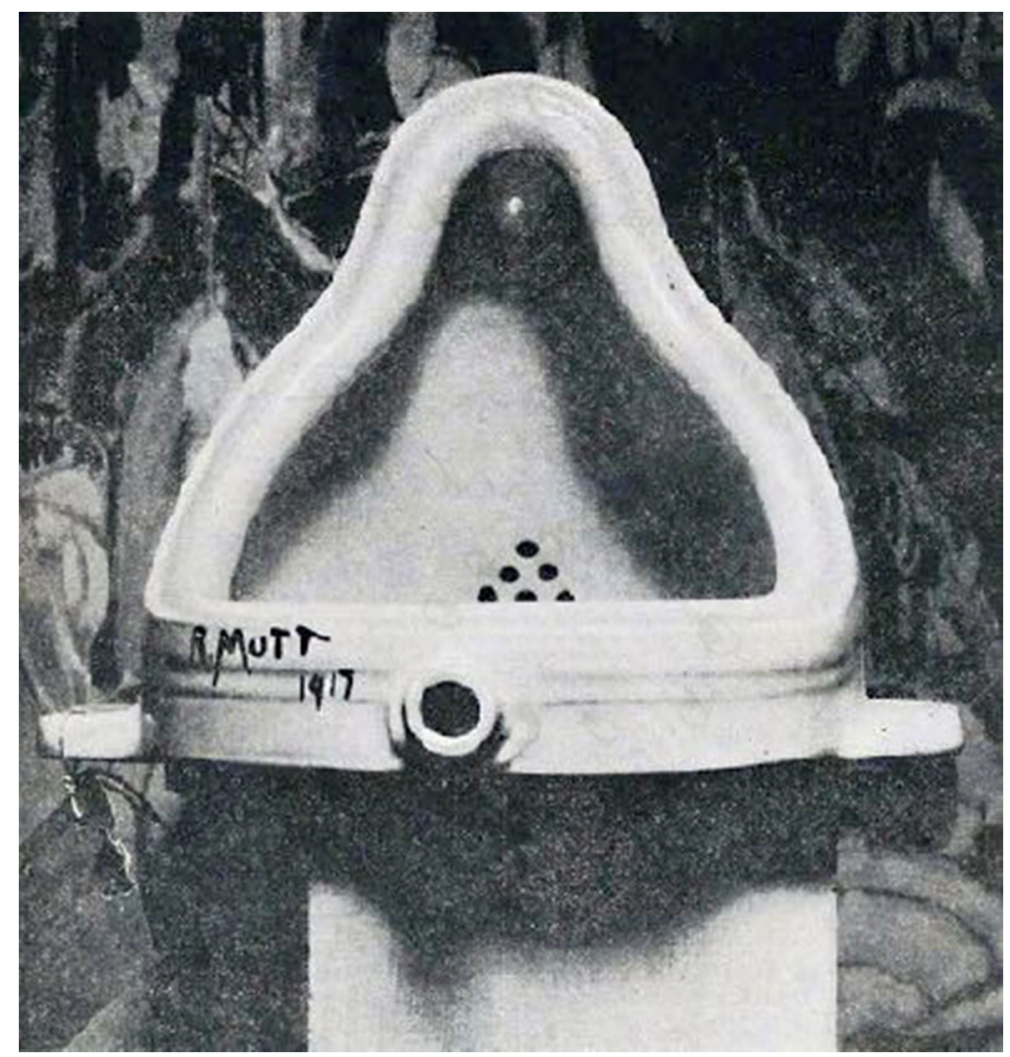

Fig. 1 Fountain, Marcel Duchamp (1917). This work was initially rejected from a gallery show, and only accepted as a work of art after Duchamp's famous name was attached. Image from Wikimedia Commons

In short, institutional support can co-opt the cognitive processes involved in ordinary communication in ways that motivate a search for more effortful interpretations - more complex, weightier and less functional - that are unlikely to be reached without some kind of prior justification for that extra effort. To be clear, we are certainly not suggesting that artists and galleries are deliberately obscurantist or disreputable in the way that intellectual gurus sometimes are (or are accused of being). We are just suggesting that the same underlying cognitive processes of interpretation apply in each case, albeit to different ends; and indeed that prompting this kind of interpretative process is a central function of both art itself and the institutional context in which it is presented.

Note also that the viewer of fine art has rather more autonomy in seeking interpretations than audiences do in ordinary conversational settings. While the speaker of an ordinary utterance might have relatively well-defined ideas of the cognitive effects their stimulus might achieve, and might hence be inclined to correct erroneous interpretations, viewers' interpretations of works of art can rarely be definitively said to be wrong. In this light, it is worthwhile to distinguish comprehension from interpretation. Deirdre Wilson introduces the difference in the context of interpretation of literary works, noting that while some meanings "will be strongly communicated..., others may be more weakly communicated, so that an addressee who decides to accept them 
must take some responsibility for their truth. As communication becomes weaker, comprehension shades off into interpretation, and communication is no longer a yesno matter but a matter of degree" (2018, p.189). Wilson emphasises that it is because the addressee takes on this responsibility in cases of weak communication that even if an artist, asked about a plausible and interesting proposed interpretation of a work, confesses that it was not specifically foreseen, it would still not be correct to say that the interpretation were wrong (see also Pignocchi 2014b).

Literature clearly involves both comprehension (of individual words and sentences) and interpretation (of the text and its broader significance) (see Cave and Wilson 2018 for a collection of work using relevance theory in literary interpretation). In the case of non-textual media it is less clear that comprehension proper comes in to play, but even so, there can be conclusions reached by its audience that can very clearly be seen to have been intended by the artist, and a range of others for which the evidence is less decisive. For example, in Frida Kahlo's Self Portrait with Monkeys (1943), it is relatively clear (even without looking at the title) that the audience is to conclude that what is depicted is a woman with monkeys (see §5), and the viewer might also come to a whole range of additional interpretations that are less clearly intended. Artworks are constructed to, quite deliberately, afford a range of weakly communicated interpretations. This interpretable quality effectively increases the potential role of credence and other institutional effects. It also helps to explain the ineffable nature of art, which turns on its capacity to create revelatory and/or non-propositional mental states rather than the more definitive impacts of strong communication.

\section{Institutions and Atmosphere}

In the tradition of painting and sculpture that formed the basis of contemporary Western gallery culture, artworks brought with them certain arguments for value that justified the place accorded to them in society. Artists would do considerable skilled technical work to make one thing look like another and the artwork's value was largely self-evident, from the price of the materials and difficulty of attaining them to the skill and time of the artist. At the same time, respect for artworks can also go beyond the self-evidence of value. In Vogel's Net: Traps as Artworks and Artworks as Traps, Alfred Gell argues that respect for making can shift into a sort of spiritual appreciation. He discusses the case of an eel trap that was more carefully and intricately made than it needed to be, and outlines the spiritual connotations of this extra level of refinement (Gell 1996). Such effects are one reason for the high status accorded to art throughout much of history.

In contrast, many modern artworks are known as artworks despite not displaying their labour-intensiveness on their sleeves; and, conversely, evidence of a maker's skill is by itself not a sufficient condition for considering it art. Nowadays, the skill of the artist as craftsperson is less readily evident. It is clear in the case of Duchamp's Bottle Rack that meanings are not inherent in the object but are teased out by the viewer when considering why the artist has chosen this particular object to be given the status of art. Yet the objects or actions so exhibited are accorded profound and wide-ranging interpretations; for example, the simple act of dropping exhibited in Ai Weiwei's Dropping a Han Dynasty Urn (1995) is typically read in terms of its cultural and political import, as a comment on the rupture between past and present. 
In contemporary Western fine art, evidence for artistic intent is most commonly provided by the setting of the gallery. While it is the case that the true story of how an object came to be displayed in a gallery may involve the actions of several decisionmakers with differing ideas and intentions, it is still an imagined artist-figure to whom the intentions are most commonly attributed, and the ceremonial treatment accorded the object by the institutional structures around it serve to enhance the viewer's credence in the profundity and complexity of those intentions $(\S 3)$. Moreover, galleries have changed greatly from the days of salon-style shows, and the more contemporary white cube style, where space is minimal and clean, can magnify these framing effects. When everyday objects can be artworks, and when viewers take cues about what has and has not been declared to be art from the institutional setting, it makes sense that we go on to treat whatever is placed within the gallery walls as intentional-a tendency that sometimes produces false positives. When a teenager left a pair of glasses on the floor of the San Francisco Museum of Modern Art, they were assumed by many viewers to be a work of modern art (Hunt 2016).

Having said that, non-white-cube venues are also sometimes used in similar ways: venues such as warehouses or old car parks can be widely seen functioning as very effective contemporary art spaces. Institutional sanctioning can be exported to works that exist in all manner of public spaces by virtue of promotion within the sphere of influence of a gallery, or the art-world culture more generally, and the extra investiture of effort can still occur. In Spiral Jetty by Robert Smithson (1970), the journey to see the artwork is in itself subjected to ceremonial treatment, and is treated as a pilgrimage (The Mythic Scale of History and Labor at Spiral Jetty n.d.). In these cases, the artwork is more likely to be large or incongruous enough to make its intentionality self-evident, and the boundary of the gallery framing is not so strictly enforced, but we also note that the particulars of the space are often also read as intentional-a decision by the art world to branch out and respond to, say, industrial spaces, public places, or nature. It is, moreover, not only a big name (of a gallery or of an artist) that can have this effect. We might also look for the "atmosphere of artistic theory, a knowledge of the history of art: an artworld" sought by Danto (1964: 201). A viewer can descry a hint that what is happening belongs to 'an artworld' - an invocation of the traditions of artistic display, a subversion of usual functionality, a certain sense of ceremony - and this can be sufficient to set in motion the kinds of interpretative activity described in $\S 3$. In such ways can assignations of status afforded to institutions affect the interpretation of the artwork they present and endorse.

Conversely, the relative absence of prior assignations of status can discourage audiences from engaging in enhanced interpretation. Numerous art theorists have noted that artistic status is differently assigned in, for instance, the way that traditionally 'men's arts' such as painting and sculpture are treated, as compared with traditionally 'women's arts' such as quilting and embroidery (e.g. Garber 1992; Collins and Sandell 1987; Parker 2010). Confronted with a beautiful depiction of a vase of lilies embroidered on a bedspread, a viewer would be likely to appreciate the skill involved in its creation. However, on encountering a depiction of a vase of lilies in a painting, a viewer would appear more likely to entertain interpretations that do not seem to be so available in the bedspread case; such as, for instance, that the artist was contemplating death and mortality. Such differences in assignation of status have been challenged by artists such as Tracy Emin, who has made use of the institutional effects granted to her as a 
prominent modern artist to take up these 'women's arts', making conscious comment on 'the art of the personal' (Parker 2010: xv).

\section{The Multiplicity of Art Experience}

In consequence of the various effects described in previous sections, viewers often produce for themselves genuinely more profound, intense experiences and ideas out of such works than they otherwise would. The work of the artist is to provide something that will reward cognitive effort (and also not curtail contemplation by putting forward a single, 'correct' answer). Many diverse works of art intentionally exhibit details of the world or ways of being so as to produce experiences that are cognitively rewarding in one way or another. There is a great skill to choosing and creating objects that will accommodate this process. Indeed, constructing artefacts that elicit and accommodate multiple, complex interpretations in the mind of a hardworking creative viewer simply is what many artists do. As Fodor suggested $(\S 1)$, good artists are skilled at making "interpretable artifacts". This task is by no means easy, and it can be reinforced by institutional effects.

For example: Lubaina Himid's Negative Positives (2007-2009), a series of works that highlight stories in British newspapers that focus on a black protagonist by selectively covering sections of pages with patterns reminiscent of African prints. Her selective, aestheticised presentation of these newspaper pages holds up the content for deeper contemplation than would be usual, this direction of enhanced attention revealing a tendency in British newspapers to place even celebratory images of black people alongside stories that push negatively-shifted narratives about black communities. But this is not simply a presentation of research data, and the interpretive process is not expected to stop at this insight. As well as pointing to a strange phenomenon, the presentation of these pages masked with colourful patterns as artworks encourages the audience to explore more subtle and speculative responses; such as, for instance, seeing them as a proposal for a Britain in which richer black stories are closer to centre-stage in the national consciousness.

For a clear example of the large role that a viewer's own contribution can have to the experience of an artwork, consider Martin Creed's The Lights Going On and Off (2000). It takes a very simple form: there is a room, and in it a light simply switches on, and then a little while later, switches off. If a viewer, having been exposed to this work in a gallery and hence experiencing it in a way that conveys a presumption of relevance (see \$2), in fact finds few if any cognitive effects beyond the proper functioning of a light switch, then she is likely to abandon the search for interpretations. If, worse, the viewer invests additional cognitive effort, perhaps in the process dredging up remembered ideas about minimalism and conceptual art, and still doesn't get much in the way of worthwhile cognitive effects in return, she might even have the sensation of having been made a fool of - or indeed she might revise her opinion of the art or the artist downward, as in the guru effect described in $\S 3$. If, on the other hand, a viewer sees this work and has been recently thinking about the changed perceptual states created by small environmental alterations, is habitually interested in thinking about ways to rethink the traditional conventions of gallery display, and happens to have 
yesterday read an article about light travelling through the universe, that person might stand in the room for hours, allowing that sensory experience to connect up with those thoughts, and thinking through Creed's previous endeavours with new eyes. This person will have an entirely different experience of the work. Factors that can affect cognitive effects, such as the frequency and recency of the viewer having entertained particular beliefs, can combine to help the viewer to reach rich and rewarding interpretations.

This effect is not, however, limited to artworks in which objects are appropriated; our claim is that enhanced interpretive work prompted by the intentional exhibition of an object or phenomenon is characteristic of modern art more broadly, and even beyond. Take for a quite different example one of Frida Kahlo's striking self-portraits, Self Portrait with Monkeys (1943), in which the artist depicts herself, fixing the viewer with a level gaze, surrounded by four black spider monkeys, which caress her neck and chest. The viewer is drawn in to contemplating the little scene. Considering why a person might have constructed this representation of herself, a viewer might notice the lush vividness of the bird of paradise flower behind her, and the sensual gentleness of the monkeys, seeming almost to cradle her, and from these form a sense of the depicted woman's vulnerability and sexuality. Or, consider Mark Rothko's Untitled (Black on Grey) (1970), a large canvas divided horizontally, black above, and a complex, textured grey below. The contemplating viewer is enveloped by the stark canvas, perhaps reading it as an empty landscape, or a void, the starkness of the line lending a sense of desolation to the painting. The colours and form, so exhibited, take on a dark significance. In both cases, certain elements are placed in the frame with clear intentionality by the artist, and the audience considers them and their import with great care-and yet the experience that this gives rise to is subtle, personal, much more a shift in perception than a message.

Collectively these examples illustrate how the presentation of an object as art can make possible particular and profound experiences that would not otherwise occur. Art is notoriously diverse and slippery to define, but in each of these cases the attribution of artistic intentions validates a complex interpretive engagement, often with objects or other phenomena that would otherwise be unremarkable. Whether the work is encountered in a gallery, a purpose-built chapel, or even reproduced in an art catalogue or website, indicators of art-status are present and important to its reception. As we discussed in $\S 3$ and $\S 4$, the degree of credence involved in accepting an object as art helps to explain why these interpretations are most commonly and readily provided by an institutional setting, whether a building, book, or website, or the "something the eye cannot descry" (Danto 1964) that situates an object in the art canon. Yet while it is prompted by a kind of intention-recognition, this interpretive process is not one of finding a simple message ( $(2)$. Himid’s Negative Positives, for instance, do not only highlight the juxtapositions found on newspaper front pages (a relatively simple message) but also effect a subtle change of perspective that could not easily be summarised; and as such they share a way of seeing, rather than a proposition (a characterisation shared by a number of theorists of art; see O'Loughlin and McCallum 2019). Indeed an essential aspect of the artist's skill is to provide prompts that reward enhanced interpretive work, that do not resolve easily into one interpretation, and which remain open and interpretable for as long as the viewer wishes to contemplate them. 


\section{Conclusion}

The art experience is a phenomenon both highly cultural and, we have argued, also deeply rooted in the particulars of human cognition and the way that communication is achieved. In the course of this paper we have shown how a cognitivist view of communication, such as relevance theory, provides a way to link individual interpretive experience with the functions fulfilled by large social structures such as institutions. In particular, it co-opts for new, interesting and rewarding purposes our distinct capacity to comprehend and interpret ostensively-presented stimuli, and it does so in an institutional and cultural context that, in general, amplifies and intensifies these effects.

One criticism sometimes levelled at the institutional perspective is that while its admittedly circular structure (as owned in Dickie 1987) does well to describe the cultural phenomenon of art, it does less well when it comes to explaining what it is that makes art valuable, what needs it serves and what it is that such a strange activity is uniquely positioned to provide (Beardsley 1976; Carroll 1994). Though we do not take ourselves to have answered this latter question, making links between the broad influence of institutions and the particulars of individual experience might lay the groundwork for such an answer. If we are able to say not just that institutional sanctioning is present and important but also to describe how its effects play out in an individual's enhanced, profound experience of a work of art-and how those effects might be leveraged in careful and precise adjustment by an artist-we are closer to understanding just what that work achieves, and what the experience does for us.

While we have focused our analysis on the contemporary art world, and the ceremonial treatment associated with white cube galleries is highly characteristic of Western fine art, our cognitivist approach and indeed many of our specific arguments and observations can, we believe, shed light on a whole range of artistic activities, if not beyond. More generally we emphasise how much is to be gained by forging these kinds of interdisciplinary links. Recognition of the adaptive features of cognition helps us to posit explanations for certain phenomena, but richer insight comes from considering how the evolved cognitive processes interact with the cultural environment in which they operate. In consequence, if we are to address the contingent reality of culturally embedded experience in ways continuous with the natural sciences, then we ought to pay close attention not only to what evolutionary, cognitive and other scientific perspectives have to offer, but also to the ways that in which the phenomena in question have been characterised and understood by theorists in the relevant domains.

Funding Information Open access funding provided by Central European University.

Open Access This article is distributed under the terms of the Creative Commons Attribution 4.0 International License (http://creativecommons.org/licenses/by/4.0/), which permits unrestricted use, distribution, and reproduction in any medium, provided you give appropriate credit to the original author(s) and the source, provide a link to the Creative Commons license, and indicate if changes were made.

\section{References}

Adorno, T. W. (1997). Aesthetic Theory. A\&C Black. (Original work published 1970). 
Barthes, R. (1978). Death of the author. In Image-music-text (pp. 143-148). Farrar, Straus and Giroux.

Beardsley, M. (1976). Is art essentially institutional? In: Culture and art (pp. 194-209). Atlantic Highlands: Humanities Press.

Brabanter, P.D. 2010. Uttering sentences made up of words and gestures. In Explicit communication, 199-216. London: Palgrave Macmillan. https://doi.org/10.1057/9780230292352_13.

Buekens, F., and J. Smit. 2018. Institutions and the Artworld - A critical note. Journal of Social Ontology 4: 53-66.

Bullot, N.J., and R. Reber. 2013. The artful mind meets art history: Toward a psycho-historical framework for the science of art appreciation. Behavioral and Brain Sciences 36 (2): 123-137. https://doi.org/10.1017 /S0140525X12000489.

Carroll, N. (1994). Identifying Art. In: Institutions of art: Reconsiderations of George Dickie's philosophy, pp. 75-100. Pennsylvania State University Press.

Carston, C. 2002. Thoughts and utterances: The pragmatics of explicit communication. Oxford: John Wiley \& Sons.

Carston, R. (2008). Relevance theory and the saying/implicating distinction. In The handbook of pragmatics (pp. 633-656). Blackwell Publishing Ltd. https://doi.org/10.1002/9780470756959.ch28

Cave, T., and D. Wilson, eds. 2018. Reading beyond the code. Oxford: Oxford University Press.

Clark, B. 2013. Relevance theory. Cambridge: Cambridge University Press.

Collins, G.C., and R. Sandell. 1987. Women's achievements in art: An issues approach for the classroom. Art Education 40 (3): 12-21. https://doi.org/10.1080/00043125.1987.11652013.

Creed, M. (2000). The lights going on and off.

Danto, A. 1964. The Artworld. Journal of Philosophy 61 (19): 571-584.

Dickie, G. (1971). Aesthetics: An introduction. Pegasus.

Dickie, G. 1987. The art circle. Philosophical Review 96: 141-146.

Duchamp, M. (1914). Bottle rack.

Duchamp, M. (1917). Fountain.

Farrell, J. (2017). The varieties of authorial intention: Literary theory beyond the intentional fallacy (1st ed. 2017 edition). New York: Palgrave Macmillan.

Fodor, J.A. 2012. Déjà vu all Over Again. In Danto and his critics, ed. M. Rollins, 55-68. London: WileyBlackwell. https://doi.org/10.1002/9781118253045.ch4.

Fokt, S. 2017. The cultural definition of art. Metaphilosophy 48 (4): 404-429.

Garber, E. 1992. Feminism, aesthetics, and art education. Studies in Art Education 33 (4): 210-225. https://doi. org/10.1080/00393541.1992.11651877.

Gell, A. 1996. Vogel's net: Traps as artworks and artworks as traps. Journal of Material Culture 1 (1): 15-38. https://doi.org/10.1177/135918359600100102.

Graham-Dixon, A. (2017, February 14). This is the modern world. Art of France. London: BBC. Retrieved from http://www.bbc.co.uk/programmes/b08flbw0.

Grice, H. P. (1989). Studies in the Way of Words. Harvard University Press.

Higgs, J. (2015, September 8). Was Marcel Duchamp's 'Fountain' actually created by a long-forgotten pioneering feminist? The Independent. Retrieved from http://www.independent.co.uk/artsentertainment/art/features/was-marcel-duchamps-fountain-actually-created-by-a-long-forgottenpioneering-feminist-10491953.html

Himid, L. (2007). Negative positives.

Hunt, E. (2016, May 27). Pair of glasses left on US gallery floor mistaken for art. The Guardian. Retrieved from http://www.theguardian.com/us-news/2016/may/27/pair-of-glasses-left-on-us-gallery-floormistaken-for-art.

Kahlo, F. (1943). Self portrait with monkeys.

Kendon, A. 2004. Gesture: Visible action as utterance. Cambridge: Cambridge University Press.

Levinson, J. 1979. Defining art historically. British Journal of Aesthetics 19 (3): 21-33.

Levinson, J. 1989. Refining art historically. The Journal of Aesthetics and Art Criticism 47 (1): 21-33. https://doi.org/10.2307/431990.

McNeill, D. 2005. Gesture and thought. 1st ed. Chicago: University of Chicago Press.

O'Loughlin, I., and K. McCallum. 2019. The aesthetics of theory selection and the logics of art. Philosophy of Science 86: 325-343.

Parker, R. (2010). The subversive stitch: Embroidery and the making of the feminine. I.B. Tauris.

Pignocchi, A. 2014a. The intuitive concept of art. Philosophical Psychology 27 (3): 425-444.

Pignocchi, A. 2014b. History and intentions in the experience of artworks. Topoi 33: 477-486.

Pignocchi, A. (2019) The continuity between art and everyday communication. In F. Cova \& S. Rehault (Dir.), Advances in Experimental Philosophy of Aesthetics (pp. 241-266). Bloomsbury.

Recanati, F. 2001. What is said. Synthese 128 (1/2): 75-91. 
Rothko, M. (1970) Untitled (Black on Grey).

Scott-Phillips, T. 2015a. Speaking our minds: Why human communication is different, and how language evolved to make it special. 2015th ed. Houndmills: Palgrave.

Scott-Phillips, T.C. 2015b. What is art? A pragmatic perspective. Think 14 (40): 87-91. https://doi.org/10.1017 /S1477175615000093.

Scott-Phillips, T.C. 2017. Pragmatics and the aims of language evolution. Psychonomic Bulletin and Review 24 (1): 186-189.

Smithson, R. (1970). Spiral Jetty.

Sperber, D. (1982) Apparently irrational beliefs. In Rationality and relativism (pp. 149-180). Blackwell.

Sperber, D. 2010. The guru effect. Review of Philosophy and Psychology 1 (4): 583-592. https://doi. org/10.1007/s13164-010-0025-0.

Sperber, D., \& Wilson, D. (1995). Relevance: Communication and cognition. Wiley.

Sperber, D., and D. Wilson. 2015. Beyond Speaker's meaning. Croatian Journal of Philosophy 15 (2): 117-149.

The Mythic Scale of History and Labor at Spiral Jetty. (n.d.). Retrieved 17 September 2017, from https://hyperallergic.com/200358/the-mythic-scale-of-history-and-labor-at-spiral-jetty/.

Tomasello, M. (2010). Origins of human communication. MIT Press.

Weiwei, A. (1995). Dropping a Hang Dynasty Urn.

Wharton, T. 2009. Pragmatics and non-verbal communication. 1st ed. Cambridge: Cambridge University Press.

Wharton, T. 2016. Paralanguage. In The Routledge handbook of pragmatics, ed. A. Barron, G. Steen, and G. Yueguo, 69-75. London: Routledge.

Wilson, D. (2011). Relevance and the interpretation of literary works. Observing Linguistic Phenomena: A Fest-schrift for Seiji Uchida, 3-19.

Wilson, D. (2018). Relevance theory and literary interpretation. Reading Beyond the Code: Literature and Relevance Theory: 185.

Wilson, D., \& Sperber, D. (1986). On Defining Relevance. In Philosophical grounds of rationality (pp. 243258). Oxford University Press.

Wilson, D., \& Sperber, D. (2004). Relevance theory. In The handbook of pragmatics (pp. 607-632). Oxford: Blackwell.

Wilson, D., and D. Sperber. 2012. Meaning and relevance. Cambridge: Cambridge University Press.

Wimsatt, W. K. and Beardsley, M. C. (1946). The intentional fallacy. The Sewanee Review, 54: 468-488

Yus, F. Relevance Theory Online Bibliographic Service. https://personal.ua.es/francisco.yus/rt.html. Accessed 17 April 2019.

Publisher's Note Springer Nature remains neutral with regard to jurisdictional claims in published maps and institutional affiliations. 